\title{
O fim da Rede Própria do Programa Farmácia Popular do Brasil e o Princípio da Proibição do Retrocesso Social
}

The end of the Own Network of the Popular Pharmacy Program of Brazil and the Principle of seal to social regression

El fin de la Red Propia del Programa Farmacia Popular de Brasil y el Principio del vedación del Retroceso Social

RESUMO. Objetivo: O presente artigo analisa o encerramento da modalidade "Rede Própria" do Programa Farmácia Popular do Brasil a luz do princípio da proibição do retrocesso social. Metodologia: Realizou-se um estudo descritivo, analítico de base documental e de abordagem qualitativa, com estudos publicados no Brasil no período de 2010 a 2017, sob a ótica das normas legislativas que regem o programa e análise dos dados disponibilizados no portal da Sala de Apoio à Gestão Estratégia do Ministério da Saúde sobre o Programa Farmácia Popular do Brasil. Resultados: O número de farmácias e adesão dos municípios foram crescendo gradativamente do início do Programa em 2004 até 2012, no ano de 2013 houve uma estagnação e após 2013 começou a diminuir o número de farmácias e consequentemente o número de municípios atendidos. Conclusão: O encerramento da modalidade "Rede Própria" do Programa Farmácia Popular do Brasil pelo Governo Federal significa um aumento no gasto das famílias brasileiras, além de denotar um retrocesso social.

Palavras-chave: Direito à Saúde. Políticas Públicas. Assistência Farmacêutica.

ABSTRACT. Objective: This article analyzes the closure of the modality "Own Network" of the Popular Pharmacy Program in Brazil in the light of the principle of seal to social regression. Methodology: A descriptive and documentary analytical study as qualitative research was performed, with studies published in Brazil between 2010-2017, from the point of view of the government program and data analysis made available by room support and strategic management portal of the Health Ministry on Brazil's Popular Pharmacy Program. Results: The number of pharmacies and adhesion of municipalities increased gradually from the beginning of the program in 2004 until 2012, in 2013 there was a stagnation and after that year began to decrease the number of pharmacies and consequently the number of municipalities served. Conclusion: The closure of the modality "Own Network" of Brazil's Popular Pharmacy Program by Federal Government means a financial increase in the budget of brazilian families, besides denoting a social regression.

Keywords: Right to Health. Public Policy. Pharmaceutical Services.

RESUMEN. Objetivo: El presente artículo analiza la clausura de la modalidad "Red Propia" del Programa Farmacia Popular de Brasil a la luz del principio del vedación del retroceso social. Metodología: Se realizó un estudio descriptivo, analítico de base

\footnotetext{
1 Pesquisadora Organizacão Pan-Americana da Saude/Organizacão Mundial da Saude, OPAS/OMS Universidade de Brasília. E-mail: joselia.trindade@gmail.com
} 
documental y de abordaje cualitativo, con estudios publicados en Brasil en el período de 2010 a 2017, bajo la óptica de las normas legislativas que rige el Programa y análisis de los datos disponibles en el portal de la Sala de Apoyo a la Gestión Estrategia del Ministerio de Salud sobre el Programa de Farmacia Popular del Brasil. Resultados: El número de farmacias y adhesión de los municipios fue creciendo gradualmente desde el inicio del programa en 2004 hasta 2012, en el año 2013 hubo un estancamiento y después de 2013 comenzó a disminuir el número de farmacias y consecuentemente el número de municipios atendidos. Conclusión: La clausura de la modalidad "Red Propia" del Programa de Farmacia Popular del Brasil por el Gobierno Federal significa un aumento financiero en el presupuesto de las familias brasileñas, además de denotar un retroceso social.

Palabras-Ilave: Derecho a la salud. Políticas Públicas. Servicios Farmacéuticos.

\section{Introdução}

\section{Direito à Saúde}

No Brasil, o direito à saúde está positivado na Constituição Federal (CF) de 1988 nos artigos 196 ao 200. Esse direito foi corporificado na CF após a Reforma Sanitária Brasileira (RSB) que foi o movimento popular que culminou na criação do Sistema Único de Saúde (SUS). Para Dallari (1), dos direitos fundamentais sociais conquistados na CF, o direito à saúde foi garantido por meio de políticas sociais e econômicas, e ainda, a autora realça que o "cuidar da saúde" é uma obrigação que deve ser de responsabilidade de todos os entes federados.

Para a efetivação dos direitos fundamentais e sociais propostos pelo texto constitucional, foi essencial um conjunto de normas capazes de estruturar e dar garantias à sociedade. Nessa perspectiva, foram criadas duas grandes normas consideradas as Leis Orgânicas da Saúde: a primeira foi a Lei 8.080, de 1990, que em seu escopo, define as diretrizes para a organização e para o funcionamento do SUS, inclusive, agrega a participação da iniciativa privada de serviços de saúde desde que contratados ou conveniados. A segunda, corresponde a Lei 8.142, também de 1990, que versa sobre a participação da comunidade na gestão do SUS e sobre as transferências intergovernamentais de recursos financeiros no âmbito do SUS (2) (3).

A Lei 8.080 foi regulamentada pelo Decreto 7.508 no ano de 2011 com o objetivo de fortalecer e ampliar as ações de serviços de saúde ofertadas pelo SUS. O decreto, dispõe ainda, sobre a organização do SUS, o planejamento da saúde, a Assistência à Saúde e a articulação interfederativa. E como mecanismo de organização dos serviços de saúde, foi definido eixos maiores (4). 
Nessa lógica, diversas outras normas jurídicas foram criadas para fortalecer o SUS desde a sua criação até este momento, como por exemplo, as Normas Operacionais Básicas (NOB/91, NOB/92, NOB/93 e NOB/96) e as Normas Operacionais da Assistência à Saúde (Noas 01/2001 e 1/2002) (5).

Foram várias as conquistas de direitos fundamentais e sociais adquiridos pela sociedade brasileira desde a promulgação da Constituinte. Nesse sentido, Giovanella (6) destaca principalmente os sistemas de saúde e as políticas de saúde que subsidiam esses direitos. Para a autora, os sistemas de saúde são formas de proteção social, no qual faz parte da seguridade social, o seguro social e a assistência social, como uma forma de garantir direitos e a criação de políticas públicas.

Para Fleury (7), as políticas de saúde - pensadas para a melhoria das condições sanitárias de uma população - devem ser tratadas como políticas sociais voltadas tanto para o indivíduo quanto para a coletividade.

\section{Princípio da proibição do retrocesso social}

O princípio da proibição do retrocesso social foi criado como estratégia para barrar as arbitrariedades exercidas pelo Poder Legislativo e Poder Executivo ao retirar direitos conquistados pela sociedade. Tal princípio surgiu na jurisprudência europeia no início na década de 70, sobretudo na Alemanha e em Portugal, no qual se iniciou com a proteção jurídica aos direitos de propriedade, direitos esses que não eram concretizados pela constituição daqueles países (8).

No Brasil, os direitos sociais estão garantidos na Carta Magna de forma permanente. Segundo estudo (9), a Constituição Federal brasileira é uma constituinte que traz no seu escopo direitos sociais definidos. A despeito dos direitos sociais conquistados na CF, há margem para o legislador modificá-los conforme a necessidade da população ou até mesmo conforme interesses políticos (8) (9). Entretanto, tal margem é mínima, e, as cláusulas pétreas, mesmo que alteradas não podem ser abolidas. Quando ocorre algum ato contra o que a população já usufruía de alguma forma, é considerado como retrocesso social.

Cunha (9), parte da premissa de que o princípio da proibição do retrocesso social seja analisado conforme as funções exercidas pelo Estado: com a administração pública e, principalmente, com as funções legislativas e judiciária. Nessa lógica, o autor, destaca 
ainda, a importância da participação dos três poderes: Executivo, Legislativo e Judiciário para a efetivação do princípio.

Nesse sentido, o Princípio da Proibição do Retrocesso Social no direito brasileiro sobrepõe ao legislador o cumprimento da efetividade dos direitos fundamentais sociais, "(...) sendo-lhe defeso atuar comissivamente em sentido oposto, tanto quanto lhe é proibido deixar de regulamentar, em sede legislativa, uma norma constitucional que lhe estabelece tal dever (10)". Como bem expressa Taveira:

percebe-se que o princípio da proibição de retrocesso decorre de modo implícito do sistema constitucional, tendo por base, principalmente, o princípio do estado democrático de direito, o princípio da dignidade da pessoa humana, o princípio da máxima eficácia e efetividade das normas definidas de direitos fundamentais, bem como as manifestações específicas definidoras de direitos fundamentais, bem como as manifestações específicas e expressamente previstas na Constituição, no que diz com a proteção contra medidas e cunho retroativo e do princípio da proteção da confiança (9).

Para Braz (11), a redução ou supressões dos direitos sociais e fundamentais, e a garantia dos progressos conquistados pela sociedade e positivados na CF podem ser compreendidos como o Princípio da Proibição do Retrocesso Social. Diante disso, Lima e Cunha (12) discorrem a respeito desse princípio no sentido de que se trata da proibição de o legislador quanto ao tentar retirar direitos sociais já adquiridos, assim, o legislador fica proibido de suprimir qualquer direito sem que haja outra forma de substituição.

Taveira e Marçal fizeram-se entender que no Princípio da Proibição do Retrocesso Social quando uma lei, ao regulamentar um direito já garantido constitucionalmente, este irá incorporar ao patrimônio jurídico da cidadania não podendo ser retirado sem antes assegurar esse direito por outros meios legais, e ainda, elencam que o Estado não deve-se apropriar do dever de prover o mínimo em função de si próprio, ou seja, não pode deixar de empregar os meios cabíveis em prol da sociedade, podendo causar sérios danos e limitações aos direitos adquiridos pela sociedade (10). Desse modo, acrescenta, ainda:

que o princípio da proibição do retrocesso social apresenta intensa relação com a proibição deficiente e da proibição de excesso, uma vez que, pelo conceito daquela, entende-se que o Estado, mediante suas prestações sociais, tem o dever de procurar maximizar o mínimo existencial, maximizando a efetividade dos direitos minimamente exigíveis, de modo que aquilo que já foi garantido ou concretizado não pode vir a ser suprimido ou limitado por qualquer ato estatal; enquanto por esta tem-se que é vedado 
ao Estado utilizar meios de caráter retrocessivo, que, embora não atinjam aqueles direitos que já foram concretizados, possam promover uma involução social, porque houve uma intervenção na sociedade além do que era necessário (10).

Não há dúvida de que o princípio da proibição do retrocesso social serve para coibir o legislador, bem como o Poder Executivo ao exercer função legislativa, com a finalidade de "brecar planos políticos que enfraqueçam os direitos fundamentais" (8).

Como enfatiza Cunha (13), tal princípio tem objetivos claros de garantir a concretização dos direitos fundamentais sociais e, mais ainda, assegurar que esses direitos sejam constitucionalmente preservados sem possibilidades de retrocessos.

\section{Programa Farmácia Popular do Brasil ${ }^{2}$}

No sentido de garantir um dos direitos fundamentais a toda população brasileira de forma equânime, o Governo Federal criou o Programa Farmácia Popular do Brasil (PFPB) com o objetivo de ampliar o acesso da população aos medicamentos, além de diminuir o impacto dos gastos no orçamento familiar com medicamentos de uso contínuo.

Inicialmente o Programa foi criado na modalidade "Rede Própria"1, por meio do Decreto no 5.090, de maio de 2004. Esse decreto regulamentou a Lei no 10.858, de 13 de abril de 2004. Tal lei trata da disponibilização de medicamentos pela Fundação Oswaldo Cruz (Fiocruz) mediante ressarcimento. No artigo 4ํㅜ do Decreto $n^{0}$ 5.090/2004 diz que o Programa foi criado como uma "alternativa de acesso", sendo complementar ao SUS, a medicamentos essenciais à saúde da população, não podendo haver substituição do acesso já existente. (14) (15).

Caracterizado como a primeira fase do PFPB, a "Rede Própria" é operacionalizada pela Fiocruz que executa a compra dos medicamentos e coordena a estruturação dos estabelecimentos, além de abastecer as unidades com os insumos e capacitar os profissionais envolvidos. Desse modo, foi firmado acordo com o Ministério da Saúde (MS), e em parceria com os Municípios, os Estados e as instituições de ensino públicas ou privadas filantrópicas (16).

\footnotetext{
${ }^{2}$ O Decreto $n^{\circ} 5.090$, de 20 de maio de 2004, diz que a modalidade "Rede Própria" do Programa Farmácia Popular do Brasil, é caracterizada como farmácia própria do Governo Federal e desenvolvida em parceria com os municípios, Estados, Distrito Federal e instituições de ensino e de saúde filantrópicas.
} 
Atualmente a "Rede Própria" possui um elenco de 112 itens mais o preservativo masculino, os quais são dispensados pelo seu valor de custo representando uma redução de até $90 \%$. A única condição para a aquisição dos medicamentos disponíveis nas unidades, neste caso, é a apresentação de receita médica ou odontológica com documento com foto que conste o número do CPF do titular (14) (20).

A outra fase do PFPB surgiu em 2006 com o nome de "Aqui Tem Farmácia Popular", por meio da Portaria n 491/06 de 09 de março de 2006. Nesse momento, foi firmado parceria entre o MS e a rede privada de farmácias e drogarias. Ademais, o credenciamento nessa categoria decorre do interesse voluntário do empresariado em firmar acordo, solicitando o seu credenciamento ao MS e se responsabilizando em cumprir todas as exigências estabelecidas pelo Programa, que vão desde a comprovação de documentos de âmbito fiscal e sanitário até a identificação visual de que naquele comércio há parceria como o Programa (16) (17).

O PFPB foi reformulado em 2011 com o lançamento da campanha "Saúde Não Tem Preço", através da Portaria no 184/11 de 03 de fevereiro de 2011, com a finalidade de fornecer medicamentos gratuitos para o tratamento da hipertensão e do diabetes. Tais medicamentos serão fornecidos tanto pela "Rede Própria" quanto pelas farmácias e drogarias credenciadas, as chamadas "Aqui Tem Farmácia Popular". Em junho do mesmo ano, o MS incluiu nesta campanha mais três medicamentos para o tratamento da asma também de forma totalmente gratuita (18).

A Portaria de no 971, de 15 de maio de 2012, regulamentou e estabeleceu regras para o PFPB até a publicação da Portaria no 111, de 28 de janeiro de 2016 que suprimiu totalmente a portaria anterior. Essa nova portaria traz algumas alterações necessárias e importantes, além de estabelecer novas definições e atualizar valores de referencia do elenco de medicamentos tanto para a "Rede Própria" quanto para o "Aqui Tem Farmácia Popular". (19).

Atualmente, o PFPB está sob a coordenação do Departamento de Assistência Farmacêutica do MS (DAF/SCTIE/MS). Desse modo, o programa tem como objetivo principal minimizar o impacto nos gastos com medicamentos no orçamento familiar, além de promover a universalização do acesso aos medicamentos por meio de convênios firmados com os Estados, Distrito Federal, Municípios e hospitais filantrópicos, bem como em rede privadas de farmácias e drogarias (14). 
Estudos já publicados evidenciam que há fragilidades no acesso e uso de medicamentos nos serviços de saúde. Como destaca Silva (16), que apesar de ser disponibilizado pelos serviços do SUS nas unidades de atendimento, o medicamento representa um gasto a mais no orçamento familiar aumentando a desigualdade social entre as famílias brasileiras. (16).

Diante do exposto, o objetivo deste trabalho é analisar o encerramento da modalidade "Rede Própria" do PFPB à luz do princípio da vedação do retrocesso social, tendo como pergunta de pesquisa: o encerramento do PFPB em 2017 viola o princípio da vedação do retrocesso social na saúde?

\section{Metodologia}

Tratou-se de um estudo descritivo, analítico de base documental e de abordagem qualitativa sobre o fim da Rede Própria do Programa Farmácia Popular do Brasil (PFPB).

Foi realizada análise sobre: o PFPB sob a ótica da Lei № 10.858, de 13 de abril de 2004 que autoriza a Fundação Oswaldo Cruz (Fiocruz) ao repasse de produtos essenciais à saúde da população; o Decreto n 5.090, de 20 de maio de 2004 que regulamenta a lei e cria o PFPB; portarias e o documento de pactuação entre a Comissão Intergestores Tripartite (CIT) e o Ministério da Saúde, cujo pacto resultou no encerramento do repasse de manutenção às unidades da Rede Própria do PFPB bem como, o fim da operacionalização das unidades pela Fundação Oswaldo Cruz. E ainda, foram analisados os dados disponibilizados no portal da Sala de Apoio à Gestão Estratégia do Ministério da Saúde sobre o PFPB, e em qual contexto o programa foi implementado e posterior foi descontinuado em 2017, por meio das portarias de desabilitação do Ministério da Saúde.

Para a discussão deste artigo e análise de dados foi realizado busca de artigos científicos publicados na Biblioteca Virtual em Saúde. Com estudos publicados no Brasil no período de 2010 a 2017 a partir dos seguintes descritores: "direito à saúde"; "assistência farmacêutica" e "políticas públicas".

Relacionado ao desenvolvimento de normas, o portal Saúde Legis foi o único banco de dados para busca da legislação pertinente ao tema.

Para a organização e análise dos dados foram utilizadas planilhas do Excel 2016, e para a análise de conteúdo foram realizadas leituras sucessivas com o objetivo de identificar fatores importantes, utilizando o método de Laurence Bardin (20). 


\section{Resultados e Discussão}

No portal do Sistema de Legislação da Saúde - Saúde Legis, foram identificadas 231 normas que versam, direta ou indiretamente, sobre o programa Farmácia Popular do Brasil.

A Portaria o 491, de 9 de março de 2006 dispõe sobre a expansão do Programa Farmácia Popular do Brasil, no qual, cria a vertente "Aqui Tem Farmácia Popular" - que é o credenciamento de farmácias e drogarias privadas, e ainda, determina os valores de referências praticados por essa modalidade. Tal portaria foi revogada pela Portaria $n^{0}$ 3.089 de 16 de dezembro de 2009, que também, foi revogada pela Portaria ํo 184 de 03 de fevereiro de 2011. Veja quadro 1.

Quadro 1. Principais normas infra-legais publicadas para a criação e a estruturação do Programa Farmácia Popular do Brasil.

\begin{tabular}{|c|c|c|c|c|}
\hline Ano & Norma & Ementa & Aplica-se-a & Situação \\
\hline 1990 & $\begin{array}{l}\text { Lei } n^{\circ}=8.080 \text {, de } \\
\quad 19.09 .1990\end{array}$ & $\begin{array}{l}\text { Dispõe sobre as condições } \\
\text { para a promoção, proteção } \\
\text { e recuperação da saúde, da } \\
\text { organização e o } \\
\text { funcionamento dos serviços } \\
\text { correspondentes, e dá } \\
\text { outras providências }\end{array}$ & $\begin{array}{l}\text { Sistema Único de Saúde - } \\
\text { Medicamentos Art. 19-M. } \\
\text { Assistência Terapêutica e } \\
\text { da Incorporação de } \\
\text { Tecnologia em Saúde) }\end{array}$ & Vigente \\
\hline 2004 & $\begin{array}{l}\text { Lei } n^{\circ} 10.858, \text { de } \\
13.04 .2004\end{array}$ & $\begin{array}{c}\text { Autoriza a Fundação } \\
\text { Oswaldo Cruz -Fiocruz a } \\
\text { disponibilizar } \\
\text { medicamentos, mediante } \\
\text { ressarcimento, e dá outras } \\
\text { providências }\end{array}$ & $\begin{array}{c}\text { Disponibilização de } \\
\text { medicamentos pela Fiocruz }\end{array}$ & Vigente \\
\hline 2004 & $\begin{array}{l}\text { Decreto } \mathrm{n}^{\circ} 5.090 \text {, de } \\
20.05 .2004\end{array}$ & $\begin{array}{c}\text { Regulamenta a Lei no } \\
\text { 10.858 de } 13.04 .2004, \text { e } \\
\text { institui o PFPB, e dá outras } \\
\text { providências }\end{array}$ & PFPB- Rede Própria & Vigente \\
\hline 2004 & $\begin{array}{l}\text { Portaria } n^{\circ} 2.587 \text {, de } \\
\quad 06.12 .2004\end{array}$ & $\begin{array}{l}\text { Institui o incentivo financeiro } \\
\text { do PFPB, e dá outras } \\
\text { providências }\end{array}$ & $\begin{array}{c}\text { Incentivo financeiro do } \\
\text { PFPB }\end{array}$ & Vigente \\
\hline 2006 & $\begin{array}{l}\text { Portaria } \mathrm{n}^{\circ} \mathrm{491} \text {, de } \\
\quad 09.03 .2006\end{array}$ & $\begin{array}{c}\text { Dispõe sobre a expansão do } \\
\text { PFPB }\end{array}$ & $\begin{array}{l}\text { Farmácias e drogarias - } \\
\text { Aqui Tem Farmácia Popular } \\
\text { e os valores de referência }\end{array}$ & $\begin{array}{c}\text { Revogada } \\
\text { pela PRT } \\
\text { GM/MS } n^{\circ} \\
3.089 \mathrm{de} \\
16.12 .2009\end{array}$ \\
\hline
\end{tabular}




\begin{tabular}{|c|c|c|c|c|}
\hline 2006 & $\begin{array}{c}\text { Portaria } \mathrm{n}^{\circ} 1.279 \text {, de } \\
\quad 19.06 .2006\end{array}$ & $\begin{array}{c}\text { Institui o Comitê } \\
\text { Multidisciplinar de } \\
\text { Assessoramento Técnico à } \\
\text { expansão do PFPB }\end{array}$ & $\begin{array}{l}\text { Designar os integrantes } \\
\text { para o comitê }\end{array}$ & Vigente \\
\hline 2007 & $\begin{array}{c}\text { Portaria } \mathrm{n}^{\circ} 1.414 \text {, de } \\
\text { 13.06.2007 }\end{array}$ & $\begin{array}{l}\text { Altera a Portaria no } 491 \text {, de } \\
09.03 .2006 \text {, que dispõe } \\
\text { sobre a expansão do PFPB }\end{array}$ & $\begin{array}{c}\text { Aquisição de medicamentos } \\
\text { indicados para tratamento } \\
\text { de doenças com maior } \\
\text { prevalência }\end{array}$ & Vigente \\
\hline 2007 & $\begin{array}{c}\text { Portaria } \mathrm{n}^{\circ} 1.767 \text {, de } \\
25.07 .2007\end{array}$ & $\begin{array}{l}\text { Dispõe sobre o modelo de } \\
\text { gestão do PFPB }\end{array}$ & $\begin{array}{l}\text { Composição do conselho } \\
\text { gestor do PFPB }\end{array}$ & $\begin{array}{l}\text { Revogada } \\
\text { pela } \\
\text { Portaria } \\
\text { GM/MS no } \\
184, \text { de } \\
03.02 .2007\end{array}$ \\
\hline 2007 & $\begin{array}{c}\text { Portaria } \mathrm{n}^{\circ} 2.589 \text {, de } \\
\quad 10.10 .2007\end{array}$ & $\begin{array}{c}\text { Institui equipe técnica com a } \\
\text { finalidade de desenvolver e } \\
\text { aprimorar soluções } \\
\text { tecnológicas destinadas a } \\
\text { incrementar a segurança e a } \\
\text { eficiência na gestão do } \\
\text { PFPB }\end{array}$ & $\begin{array}{l}\text { Designar os integrantes } \\
\text { para a equipe técnica que } \\
\text { irá representar o MS. }\end{array}$ & Vigente \\
\hline 2009 & $\begin{array}{c}\text { Portaria no } 749 \text {, de } \\
\text { 15.04.2009 }\end{array}$ & $\begin{array}{c}\text { Dispõe sobre a expansão do } \\
\text { PFPB - Aqui Tem Farmácia } \\
\text { Popular }\end{array}$ & $\begin{array}{c}\text { Das normas de operação e } \\
\text { funcionamento da expansão } \\
\text { do PFPB }\end{array}$ & $\begin{array}{c}\text { Revogada } \\
\text { pela PRT } \\
\text { GM/MS } n^{\circ} \\
3.080 \mathrm{de} \\
16.12 .2009\end{array}$ \\
\hline 2009 & $\begin{array}{l}\text { Portaria } \mathrm{n}^{\circ} 3.089 \text {, de } \\
\quad 16.12 .2009\end{array}$ & $\begin{array}{c}\text { Dispõe sobre a expansão do } \\
\text { PFPB - Aqui Tem Farmácia } \\
\text { Popular }\end{array}$ & $\begin{array}{c}\text { Das normas de operação e } \\
\text { funcionamento da expansão } \\
\text { do PFPB }\end{array}$ & $\begin{array}{c}\text { Revogada } \\
\text { pela PRT } \\
\text { GM/MS no } \\
184 \mathrm{de} \\
03.02 .2011\end{array}$ \\
\hline 2010 & $\begin{array}{c}\text { Portaria } \mathrm{n}^{\circ} 367 \text {, de } \\
17.02 .2010\end{array}$ & $\begin{array}{c}\text { Inclui o medicamento } \\
\text { Fosfato de Osltamivir no } \\
\text { PFPB - Aquí Tem Farmácia } \\
\text { Popular, e define os valores } \\
\text { de referência para as suas } \\
\text { apresentações }\end{array}$ & $\begin{array}{l}\text { Elenco de medicamentos da } \\
\text { expansão do PFPB no Aquí } \\
\text { Tem Farmácia Popular }\end{array}$ & Vigente \\
\hline 2010 & $\begin{array}{c}\text { Portaria } \mathrm{n}^{\circ} 472 \text {, de } \\
\quad 04.03 .2010\end{array}$ & $\begin{array}{c}\text { Dispõe sobre a } \\
\text { disponibilização do } \\
\text { medicamento Fosfato de } \\
\text { Osltamivir nas unidades da } \\
\text { Rede Própria do PFPB }\end{array}$ & $\begin{array}{c}\text { Elenco de medicamentos da } \\
\text { expansão do PFPB nas } \\
\text { unidades da Rede Própria }\end{array}$ & Vigente \\
\hline
\end{tabular}




\begin{tabular}{|c|c|c|c|c|}
\hline 2010 & $\begin{array}{l}\text { Portaria no } 947 \text {, de } \\
\quad 27.04 .2010\end{array}$ & $\begin{array}{c}\text { Amplia a cobertura do PFPB } \\
\text { - Aquí Tem Farmácia } \\
\text { Popular }\end{array}$ & $\begin{array}{c}\text { Das normas de operação e } \\
\text { funcionamento da expansão } \\
\text { do PFPB }\end{array}$ & $\begin{array}{c}\text { Revogada } \\
\text { pela PRT } \\
\text { GM/MS no } \\
184 \mathrm{de} \\
03.02 .2011\end{array}$ \\
\hline 2010 & $\begin{array}{l}\text { Portaria } \mathrm{n}^{\circ} 2.139, \text { de } \\
\quad 28.07 .2010\end{array}$ & $\begin{array}{c}\text { Institui grupo de trabalho } \\
\text { com a finalidade de elaborar } \\
\text { diretrizes e estratégias para } \\
\text { a organização, } \\
\text { fortalecimento e } \\
\text { aprimoramento das ações e } \\
\text { serviços das farmácias } \\
\text { hospitalares no âmbito dos } \\
\text { hospitais, clínicas e } \\
\text { estabelecimentos } \\
\text { congêneres }\end{array}$ & $\begin{array}{c}\text { Grupo de trabalho formado } \\
\text { por representantes das } \\
\text { seguintes áreas: } \\
\text { DAF/SCTIE/MS; SAS/MS; } \\
\text { ANVISA; ANS; CONASS; } \\
\text { CONASEMS; CFF; CNS e } \\
\text { SBRAFH. Coordenado pro } \\
\text { DAF/SCTIE/MS. }\end{array}$ & Vigente \\
\hline 2010 & $\begin{array}{l}\text { Portaria } \mathrm{n}^{\circ} 3.219, \mathrm{de} \\
\quad 21.10 .2010\end{array}$ & $\begin{array}{c}\text { Amplia a cobertura do PFPB } \\
\text { - Aquí Tem Farmácia } \\
\text { Popular }\end{array}$ & $\begin{array}{l}\text { Elenco de medicamentos da } \\
\text { expansão do PFPB no Aquí } \\
\text { Tem Farmácia Popular }\end{array}$ & $\begin{array}{c}\text { Revogada } \\
\text { pela PRT } \\
\text { GM/MS no } \\
184 \mathrm{de} \\
03.02 .2011\end{array}$ \\
\hline 2011 & $\begin{array}{l}\text { Portaria } \mathrm{n}^{\circ} 185, \text { de } \\
\quad 03.02 .2011\end{array}$ & $\begin{array}{c}\text { Institui o comitê técnico de } \\
\text { acompanhamento do PFPB } \\
\text { - Aquí Tem Farmácia } \\
\text { Popular }\end{array}$ & $\begin{array}{c}\text { Comitê técnico formado por } \\
\text { representantes de diversas } \\
\text { áreas }\end{array}$ & Vigente \\
\hline 2011 & $\begin{array}{l}\text { Portaria } \mathrm{n}^{\circ} 184 \text {, de } \\
\quad 03.02 .2011\end{array}$ & Dispõe sobre o PFPB & $\begin{array}{l}\text { A campanha "Saúde Não } \\
\text { Tem Preço - SNTP. } \\
\text { Disponibilização de } \\
\text { medicamentos gratuitos } \\
\text { para hipertensão, diabetes e } \\
\text { asma no "Aqui Tem } \\
\text { Farmácia Popular". }\end{array}$ & Vigente \\
\hline 2011 & $\begin{array}{c}\text { Portaria no } 233 \text {, de } \\
11.02 .2011\end{array}$ & $\begin{array}{l}\text { Inclui o medicamento } \\
\text { Cloridrato de Metformina, } \\
\text { comprimido de ação } \\
\text { prolongada no PFPB - Aquí } \\
\text { Tem Farmácia Popular, e } \\
\text { define os valores de } \\
\text { referência para as suas } \\
\text { apresentações }\end{array}$ & $\begin{array}{l}\text { Elenco de medicamentos do } \\
\text { Aquí Tem Farmácia Popular }\end{array}$ & Vigente \\
\hline
\end{tabular}




\begin{tabular}{|c|c|c|c|c|}
\hline 2011 & $\begin{array}{c}\text { Portaria no }{ }^{\circ} 454 \text {, de } \\
16.03 .2011\end{array}$ & $\begin{array}{c}\text { Altera o } 2^{\circ} \text { do art. } 1^{\circ} \text { da } \\
\text { portaria } n^{\circ} 472 / \mathrm{GM} / \mathrm{MS} \text {, de } 4 \\
\text { de março de } 2010 \text {, que } \\
\text { dispõe sobre a } \\
\text { disponibilidade do } \\
\text { medicamento Fosfato de } \\
\text { Osltamivir nas unidades } \\
\text { Rede Própria do PFPB. }\end{array}$ & $\begin{array}{c}\text { Alteração do captu na } \\
\text { portaria no } 472 / G M / M S \text {, de } 4 \\
\text { de março de } 2010\end{array}$ & Vigente \\
\hline 2011 & $\begin{array}{c}\text { Portaria } n^{\circ} 726 \text {, de } \\
11.04 .2011\end{array}$ & $\begin{array}{c}\text { Altera o } 2^{\circ} \text { do art. } 52 \text { da } \\
\text { portaria } \mathrm{n}^{\circ} \text { 184/GM/MS, de } 3 \\
\text { de fevereiro de } 2011 \text {, que } \\
\text { dispõe sobre o PFPB. }\end{array}$ & $\begin{array}{c}\text { Alteração do captu na } \\
\text { portaria } \mathrm{n}^{0} 184 / \mathrm{GM} / \mathrm{MS} \text {, de } 3 \\
\text { de fevereiro de } 2011\end{array}$ & Vigente \\
\hline 2012 & $\begin{array}{c}\text { Portaria no } 971 \text {, de } \\
17.05 .2012\end{array}$ & Dispõe sobre o PFPB & $\begin{array}{l}\text { Definição de distribuição de } \\
\text { correlatos pelas Farmácias } \\
\text { e drogarias da rede privada }\end{array}$ & $\begin{array}{l}\text { Revogada } \\
\text { pela } \\
\text { Portaria } \mathrm{n}^{\circ} \\
111 \text {, de } \\
28.01 .2016\end{array}$ \\
\hline 2012 & $\begin{array}{c}\text { Portaria ํo } 1.146 \text {, de } \\
01.06 .2012\end{array}$ & $\begin{array}{c}\text { Altera e acresce dispositivos } \\
\text { à Portaria no } 971 / \text { GM/MS, } \\
\text { de } 17.05 .2012 \text {, para ampliar } \\
\text { a cobertura da gratuidade } \\
\text { no âmbito do PFPB }\end{array}$ & $\begin{array}{c}\text { Amplia a cobertura da } \\
\text { gratuidade no âmbito do } \\
\text { PFPB }\end{array}$ & Vigente \\
\hline 2013 & $\begin{array}{c}\text { Portaria } \mathrm{n}^{0} 271 \\
27.02 .2013\end{array}$ & $\begin{array}{c}\text { Institui a Base Nacional de } \\
\text { dados de ações e serviços } \\
\text { da Assistência } \\
\text { Farmacêutica e regulamenta } \\
\text { o conjunto de dados, fluxo e } \\
\text { cronograma de envio } \\
\text { referente ao Componente } \\
\text { Básico da assistência } \\
\text { Farmacêutica no âmbito do } \\
\text { SUS }\end{array}$ & $\begin{array}{l}\text { Regula o conjunto de dados, } \\
\text { fluxo e cronograma de envio } \\
\text { referente ao Componente } \\
\text { Básico da assistência } \\
\text { Farmacêutica no âmbito do } \\
\text { SUS }\end{array}$ & Vigente \\
\hline 2014 & $\begin{array}{c}\text { Portaria no } 1.019 \text {, de } \\
21.05 .2014\end{array}$ & $\begin{array}{c}\text { Altera a Portaria no } \\
2.587 / \mathrm{GM} / \mathrm{MS} \text {, de } \\
06.12 .2004, \text { que institui o } \\
\text { incentivo financeiro do } \\
\text { PFPB, e dá outras } \\
\text { providências }\end{array}$ & $\begin{array}{l}\text { Incentivo financeiro para } \\
\text { cada unidade em que } \\
\text { estiver funcionando } \\
\text { regularmente o PFPB, para } \\
\text { à cobertura de gastos com a } \\
\text { manutenção }\end{array}$ & Vigente \\
\hline
\end{tabular}




\begin{tabular}{|c|c|c|c|c|}
\hline 2016 & $\begin{array}{c}\text { Portaria no } 111 \text {, de } \\
28.01 .2016\end{array}$ & Dispõe sobre o PFPB & $\begin{array}{l}\text { Disposições gerais; da } \\
\text { operacionalização e do } \\
\text { funcionamento da PFPB - } \\
\text { do Aquí Tem farmácia } \\
\text { Popular e do modelo e } \\
\text { gestão da Rede Própria. }\end{array}$ & Vigente \\
\hline 2016 & $\begin{array}{l}\text { Portaria no 957, de } \\
\quad 10.05 .2016\end{array}$ & $\begin{array}{l}\text { Estabelece o conjunto de } \\
\text { dados e eventos referentes } \\
\text { aos medicamentos e } \\
\text { insumos da Relação } \\
\text { Nacional de Medicamentos } \\
\text { Essenciais (RENAME) e do } \\
\text { PFPB para composição da } \\
\text { Base Nacional de Dados de } \\
\text { Ações e Serviços da } \\
\text { assistência Farmacêutica no } \\
\text { âmbito do SUS. }\end{array}$ & $\begin{array}{l}\text { Conjunto de dados e } \\
\text { eventos referentes aos } \\
\text { medicamentos e insumos da } \\
\text { relação nacional de } \\
\text { medicamentos essenciais } \\
\text { (RENAME) }\end{array}$ & Vigente \\
\hline 2017 & $\begin{array}{l}\text { Portaria no } 937 \text {, de } \\
\quad 07.04 .2017\end{array}$ & $\begin{array}{c}\text { Altera a Portaria no } \\
\text { 111/GM/MS, de } 28.01 .2016, \\
\text { que dispõe sobre o PFPB, } \\
\text { para ampliar a cobertura de } \\
\text { fraldas geriátricas às } \\
\text { pessoas com deficiência. }\end{array}$ & $\begin{array}{l}\text { Amplia a cobertura de } \\
\text { fraldas geriátricas às } \\
\text { pessoas com idade igual ou } \\
\text { superior a } 60 \text { anos ou } \\
\text { pessoa com deficiência. }\end{array}$ & Vigente \\
\hline 2017 & $\begin{array}{c}\text { Portaria no } 1.182, \text { de } \\
18.05 .2017\end{array}$ & 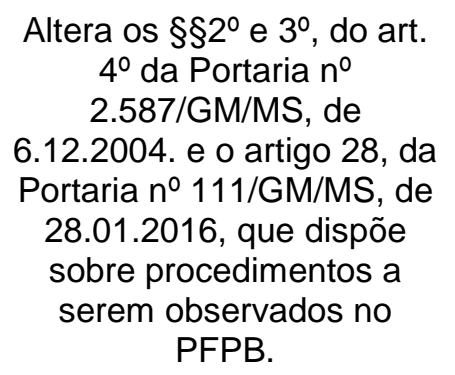 & $\begin{array}{l}\text { A apresentação da conta } \\
\text { corrente, tornar-se a } \\
\text { requisito indispensáveis á } \\
\text { habilitação dos agentes } \\
\text { cadastrados no PFPB }\end{array}$ & Vigente \\
\hline
\end{tabular}

Fonte: elaborado pela autora com base nos dados das normas legislativas sobre o Programa Farmácia Popular do Brasil

Ademais, a Portaria no 971, de 15 de maio de 2012, foi revogada pela atual Portaria no 111, de 28 de janeiro de 2016 - que rege o PFPB nas duas modalidades: 1) farmácia popular "Rede Própria" que são parcerias com os Estado, Distrito Federal, Municípios, Instituições de Ensino e Hospitais Filantrópicos; e 2) "Aqui Tem Farmácia Popular" constituído por meio de convênios com farmácias e drogarias privadas. 
As duas modalidades disponibilizam medicamentos e correlatos diferentes para a cura ou controle de doenças crônicas prevalentes na população. São medicamentos e correlatos disponibilizados para tratamentos de Doença de Parkinson, Osteoporose, Glaucoma, Hipertensão Arterial, Diabetes Mellitus, Asma, Contracepção, Dislipidemia e Rinite. Essa relação de medicamentos e correlatos se encontram nos anexos II, III e IV da referida Portaria ํo 111, de 28 de janeiro de 2016.

Além disso, o MS lançou em 2011 a campanha "Saúde Não Tem Preço" com a publicação da Portaria № 184, de 03 de fevereiro de 2011 com o objetivo de facilitar ainda mais o acesso da população a medicamentos essenciais. Essa campanha é destinada a disponibilização de medicamentos gratuitos para hipertensão, diabetes e asma, nas farmácias e drogarias credenciadas do PFPB. O quadro 2 apresenta quais esses medicamentos disponibilizados de forma totalmente gratuito.

Quadro 2. Lista de Medicamentos gratuitos do "Saúde Não Tem Preço" do Programa Farmácia Popular do Brasil.

\begin{tabular}{|c|c|}
\hline Medicamento & Indicação \\
\hline Atenolol 25mg & \multirow{6}{*}{ Hipertensão (pressão alta) } \\
\hline Captopril 25mg & \\
\hline Cloridrato de Propranolol 40mg & \\
\hline Hidroclorotiazida $25 \mathrm{mg}$ & \\
\hline Losartana Potássica 50mg & \\
\hline Maleato de Enalapril $10 \mathrm{mg}$ & \\
\hline Cloridrato de Metformina 500mg & \multirow{6}{*}{ Diabetes } \\
\hline Cloridrato de Metformina 500mg - ação prolongada & \\
\hline Cloridrato de Metformina $850 \mathrm{mg}$ & \\
\hline Glibenclamida 5mg & \\
\hline Insulina Humana 100UI/ML & \\
\hline Insulina Humana Regular 100UI/ML & \\
\hline Brometo de Ipratrópio $0,02 \mathrm{mg}$ & \multirow{7}{*}{ Asma } \\
\hline Brometo de Ipratrópio $0,25 \mathrm{mg}$ & \\
\hline Dipropionato de Beclometsona $50 \mathrm{mcg}$ & \\
\hline Dipropionato de Beclometsona $200 \mathrm{mcg}$ & \\
\hline Dipropionato de Beclometsona $250 \mathrm{mcg}$ & \\
\hline Sulfato de Salbutamol $5 \mathrm{mg}$ & \\
\hline Sulfato de Salbutamol $100 \mathrm{mcg}$ & \\
\hline
\end{tabular}

Fonte: elaborado pela autora a partir da Portaria ํㅡ 184, de 03 de fevereiro de 2018. 
Essa estrutura antes definida desde 2004 com o início do PFPB, foi modificada com o fim da modalidade "Rede Própria". Tal decisão foi tomada após discussão entre o Ministério da Saúde e a CIT (Comissão Intergestores Tripartite), reunião realizada no dia 30 de março de 2017. Conforme Nota Informativa no 18/2017 do Conselho Nacional de Secretarias Municipais de Saúde (Conasems).

Nesta reunião ficou decidido pelo fim do repasse de manutenção às unidades da "Rede Própria" do PFPB, o valor de R\$ 12.500,00 (doze mil e quinhentos reais), bem como a operacionalização das unidades pela Fiocruz. Ficou decidido a ampliação de recursos, passando de $R \$ 5,10$ para $R \$ 5,58$ por pessoa, mensalmente, para os municípios efetuar a compra de medicamentos do Componente Básico da Assistência Farmacêutica.

O repasse fundo a fundo passará de $R \$ 5,10$ para $R \$ 5,58$ por pessoa, mensalmente, para suprir a falta do funcionamento das unidades "Rede Própria" do PFPB e, contudo, dar mais liberdade aos municípios na aquisição dos medicamentos nos serviços da Atenção Básica conforme a sua especificidade.

Após a pactuação pelo MS e a CIT, foi expedido pelo Departamento de Assistência Farmacêutica do Ministério da Saúde o Ofício Circular de ํㅜ 7/2017, em 28 de abril de 2017, com o objetivo de informar os municípios da pactuação, como bem expressa através de seu assunto: "Informações sobre o fim do repasse de manutenção às unidades de Rede Própria do Programa Farmácia Popular do Brasil".

O Ministério da Saúde publicará as portarias especificas de desabilitação de cada unidade "Rede Própria" conforme cronograma de realocação do repasse pelo Departamento de Assistência Farmacêutica (DAF/MS). Enquanto as portarias não são publicadas para determinada unidade, esta unidade continuará funcionando normalmente, inclusive, recebendo o repasse de manutenção, no valor de $R \$ 12.500,00$ (doze mil e quinhentos reais), mensalmente.

Conforme dados retirados do Sistema de Legislação da Saúde (SAÚDE LEGIS), até o momento, após a pactuação, já foram desabilitadas 25 (vinte e cinco) unidades da 'Rede Própria" do PFPB com publicação seguindo a ordem do cronograma.

Estudos já publicados evidenciam que há fragilidades no acesso e uso de medicamentos nos serviços de saúde da Atenção Básica. Nesse sentido, destaca Silva (15) que, apesar de ser disponibilizado pelos serviços do SUS nas unidades de atendimento, o medicamento representa um gasto a mais no orçamento familiar 
aumentando a desigualdade social entre as famílias brasileiras, o que ratifica o retrocesso praticado pelo Governo Federal.

Com o fechamento das unidades Rede Própria, manteve-se a parceria com a rede privada denominada "Aqui Tem Farmácia Popular". Entretanto, nos municípios menores do país, ou até mesmo nas periferias dos grandes centros, permanece a ausência de farmácias e drogarias. Silva (15) aponta, ainda, que a supressão de direitos adquiridos aumenta a dificuldade no acesso de milhares de pessoas principalmente nas famílias economicamente mais pobres. A tabela 1 apresenta a correlação de farmácias em funcionamentos e o número de municípios com cobertura do Programa Farmácia Popular do Brasil.

Tabela 1. Quantidade de farmácias em funcionamento e número de municípios que aderiram o Programa Farmácia Popular do Brasil Rede Própria, entre 2004 a junho 2017.

\begin{tabular}{lll}
\hline Ano & $\mathrm{N}^{\circ}$ de Farmácias & $\mathrm{N}^{\circ}$ de Municípios Atendidos \\
\hline 2004 & 27 & 7 \\
2005 & 75 & 47 \\
2006 & 259 & 206 \\
2007 & 407 & 321 \\
2008 & 504 & 391 \\
2009 & 530 & 407 \\
2010 & 543 & 420 \\
2011 & 555 & 420 \\
2012 & 558 & 435 \\
2013 & 546 & 441 \\
2014 & 532 & 432 \\
2015 & 523 & 414 \\
1016 & 517 & 410 \\
1017 & 497 & 402 \\
\hline
\end{tabular}

Fonte: SAGE/MS 2017. (Acessado em 13.11.17)

O número de farmácias e a adesão dos municípios foram crescendo gradativamente e, no ano de 2012, houve a maior aderência dos municípios com 558 farmácias em 441 municípios. Entretanto, o número de farmácias em funcionamento seguiu uma tendência de queda a partir de 2012 , o que significa $10,9 \%$ a menos de farmácias e, portanto, $8,84 \%$ menos municípios atendidos pelo PFPB "Rede Própria”. 
Tabela 2. Quantidade de farmácias em funcionamento e número de municípios atendidos pela vertente "Rede Própria" por região do país nos anos de 2004 a junho de 2017.

\begin{tabular}{|c|c|c|c|c|c|c|}
\hline Ano & Categorias & Região Norte & Região Nordeste & Região Centro -Oeste & Região Sudeste & Região Sul \\
\hline & População & 17.740 .418 & 56.915 .936 & 15.660 .988 & 86.356 .952 & 29.439 .77 \\
\hline & Total municípios & 450 & 1.794 & 467 & 1.668 & 1.191 \\
\hline \multirow{2}{*}{2004} & $\mathrm{~N}^{\circ}$ Farmácias em funcionamento & 0 & 7 & 1 & 18 & 1 \\
\hline & Qtd de municípios atendidos & 0 & 3 & 1 & 2 & $\overline{1}$ \\
\hline \multirow{2}{*}{2005} & $\mathrm{~N}^{\circ}$ Farmácias em funcionamento & 5 & 21 & 4 & 40 & 5 \\
\hline & Qtd de municípios atendidos & 4 & 15 & 3 & 20 & 5 \\
\hline \multirow{2}{*}{2006} & $\mathrm{~N}^{\circ}$ Farmácias em funcionamento & 24 & 91 & 12 & 97 & 35 \\
\hline & Qtd de municípios atendidos & 21 & 68 & 11 & 73 & 33 \\
\hline \multirow{2}{*}{2007} & $\mathrm{~N}^{\circ}$ Farmácias em funcionamento & 55 & 137 & 20 & 147 & 48 \\
\hline & Qtd de municípios atendidos & 44 & 101 & 17 & 114 & 45 \\
\hline \multirow{2}{*}{2008} & $\mathrm{~N}^{\circ}$ Farmácias em funcionamento & 68 & 172 & 28 & 176 & 60 \\
\hline & Qtd de municípios atendidos & 51 & 124 & 23 & 136 & 57 \\
\hline \multirow{2}{*}{2009} & $\mathrm{~N}^{\circ}$ Farmácias em funcionamento & 73 & 177 & 30 & 188 & 62 \\
\hline & Qtd de municípios atendidos & 54 & 127 & 24 & 145 & 57 \\
\hline \multirow{2}{*}{2010} & $\mathrm{~N}^{\circ}$ Farmácias em funcionamento & 76 & 182 & 32 & 188 & 65 \\
\hline & Qtd de municípios atendidos & 57 & 133 & 26 & 145 & 59 \\
\hline \multirow{2}{*}{2011} & $\mathrm{~N}^{\circ}$ Farmácias em funcionamento & 75 & 188 & 33 & 193 & 66 \\
\hline & Qtd de municípios atendidos & 58 & 140 & 29 & 146 & 62 \\
\hline \multirow{2}{*}{2012} & $\mathrm{~N}^{\circ}$ Farmácias em funcionamento & 75 & 192 & 32 & 194 & 65 \\
\hline & Qtd de municípios atendidos & 58 & 144 & 30 & 149 & 60 \\
\hline \multirow{2}{*}{2013} & $\mathrm{~N}^{\circ}$ Farmácias em funcionamento & 75 & 191 & 31 & 193 & 56 \\
\hline & Qtd de municípios atendidos & 58 & 143 & 29 & 148 & 54 \\
\hline \multirow{2}{*}{2014} & $\mathrm{~N}^{\circ}$ Farmácias em funcionamento & 75 & 191 & 32 & 182 & 52 \\
\hline & Qtd de municípios atendidos & 58 & 144 & 29 & 141 & 50 \\
\hline \multirow{2}{*}{2015} & $\mathrm{~N}^{\circ}$ Farmácias em funcionamento & 75 & 190 & 31 & 177 & 49 \\
\hline & Qtd de municípios atendidos & 58 & 144 & 28 & 137 & 47 \\
\hline \multirow{2}{*}{2016} & $\mathrm{~N}^{\circ}$ Farmácias em funcionamento & 75 & 190 & 30 & 175 & 47 \\
\hline & Qtd de municípios atendidos & 58 & 143 & 27 & 137 & 45 \\
\hline \multirow{2}{*}{2017} & $\mathrm{~N}^{\circ}$ Farmácias em funcionamento & 75 & 186 & 29 & 162 & 45 \\
\hline & Qtd de municípios atendidos & 58 & 141 & 26 & 133 & 44 \\
\hline
\end{tabular}

Fonte: SAGE/MS 2017 (Acessado em 13.11.17)

A tabela 2 apresenta a quantidade de farmácias em funcionamento e os municípios atendidos, modalidade "Rede Própria", por cada região do país. A região norte, a menos povoada do país, só aderiu ao Programa em 2005 com quatro municípios e cinco farmácias. Em 2006, esse número aumentou para 24 farmácias em 21 municípios atendidos, em 2007 para 55 em 44 municípios e esse número foi aumentando aos poucos até 2011 que estagnou em 75 farmácias com cobertura para 58 municípios até junho de 2017.

A região sudeste no início do programa teve uma aderência de 18 farmácias com cobertura para dois municípios. Em 2005, houve um incremento para 40 farmácias e 20 municípios atendidos. Observa-se na tabela que em quase todas as regiões houve aumentos significativos desde o início em 2004 até 2012 e após esse ano começou a diminuir a adesão dos municípios. A região sudeste fechou o mês de junho de 2017 com 162 farmácias e 133 municípios atendidos seguindo a tendência do restante do país. 
A região nordeste, no começo do programa em 2004, iniciou com sete farmácias com cobertura para três municípios e assim como as outras regiões houve aumento gradativo até o ano de 2012. A partir de 2013 a quantidade de farmácias diminuiu gradativamente até chegar a junho de 2017 com 186 farmácias que cobriam 141 municípios.

A região sul, iniciou o programa com uma farmácia e um município atendido. Em 2005 passou para cinco farmácias e cinco municípios, em 2011 chegou a atingir 66 farmácias e 62 municípios cobertos, contudo, tais números caíram para 45 e 44 respetivamente em 2017.

Por último, a região centro-oeste que tal qual a região sul, iniciou o programa com apenas uma farmácia e um município atendido - em 2005 passou para quatro farmácias e três municípios, em 2006 para 12 farmácias e 11 municípios e assim paulatinamente até 2011 quando teve o maior número de farmácias com 33 e 29 municípios atendidos, no entanto, esse número atingiu o mínimo de 29 farmácias e 26 municípios em 2017.

Cada uma dessas unidades "Rede Própria" recebia do MS um valor de $\mathrm{R} \$ 12.500,00$. As unidades que ainda não foram desabilitadas continuam recebendo mensalmente para manutenção das mesmas.

Tabela 3. Números de farmácias e drogarias privadas do "Aqui Tem Farmácia Popular", quantidade de municípios atendidos e valores de transferência direta por região desde 2006 a maio 2017.

\begin{tabular}{|c|c|c|c|}
\hline Ano & № de Farmácias & $\mathrm{N}^{0}$ Municípios Atendidos & Valores Repassados \\
\hline 2006 & 2.955 & 594 & $34.723 .571,02$ \\
\hline 2007 & 5.052 & 1.032 & $157.103 .307,22$ \\
\hline 2008 & 6.459 & 1.228 & $323.782 .709,72$ \\
\hline 2009 & 10.790 & 1.944 & $287.572 .686,37$ \\
\hline 2010 & 14.003 & 2.467 & $247.220 .802,09$ \\
\hline 2011 & 20.225 & 3.248 & $831.085 .836,72$ \\
\hline 2012 & 25.122 & 3.730 & 1.397.609.872,36 \\
\hline 2013 & 29.559 & 4.119 & 1.862.183.889,07 \\
\hline 2014 & 33.264 & 4.345 & $2.411 .830 .647,10$ \\
\hline 2015 & 34.625 & 4.445 & 2.897.877.536,02 \\
\hline 2016 & 34.616 & 4.469 & 2.683.197.936,99 \\
\hline 2017 & 34.543 & 4.463 & 2.103.961.893,04 \\
\hline
\end{tabular}

Fonte: SAGE/MS 2017 (Acessado em 30.11.17) 
Vê-se, na tabela 3, que o número de farmácias e drogarias conveniadas passou de 2.955 (duas mil novecentos e cinquenta e cinco) em 2006, do início do programa, para 34.543 (trinta e quatro mil quinhentos e quarenta e três) até maio de 2017, caracterizando um aumento de $1.068,97 \%$ de farmácias, ou seja, houve um incremento de 11,7 vezes comparando o número inicial. Observa-se que o número de farmácias cresceu gradativamente com uma leve queda a partir de 2015 até maio de 2017 e consequentemente o número de municípios atendidos também diminuiu. $O$ repasse para 0 ano de 2017 superou dois bilhões de reais.

\section{Conclusão}

O Programa Farmácia Popular do Brasil (PFPB) "Rede Própria" começou em 2004 com 27 farmácias, com cobertura para sete municípios. Esse número cresceu gradativamente até o ano de 2012 quando atingiu 558 farmácias em 441 municípios atendidos. A partir de 2013 tais números decresceram, havendo uma queda de 10,9\% para a quantidade de farmácias e 8,84\% para o número de municípios atendidos.

Quando se compara a quantidade de farmácias por região, as diferenças tornam-se mais perceptíveis. A região norte diminuiu 1,3\%. Ao tempo que na região nordeste houve um decréscimo de 3,1\%, e 16,4\% na região sudeste. Na região centro-oeste ocorreu uma queda de $12,1 \%$ enquanto na região sul o declínio foi de $31,8 \%$, no período de 2011 a junho de 2017.

Nota-se que alguns municípios já vinham se desligando da modalidade "Rede Própria” desde 2013. Apesar disso, a decisão de fechar todas as unidades do país, significa perda de direitos adquiridos, além de constituir um retrocesso com severas consequências para grande parcela da população principalmente para aqueles municípios que não solicitaram o encerramento.

Mesmo, com o aumento de $R \$ 5,10$ para $R \$ 5,58$ por pessoa, mensalmente, para compra de medicamentos, se a assistência farmacêutica do município não estiver estruturada, tal medida torna-se ineficaz.

A modalidade "Aqui Tem Farmácia Popular" que é a rede Conveniada entre o MS e a rede privada de farmácias e drogarias, teve início no ano de 2006, também evidencia queda na adesão a partir de 2016 a maio de 2017.

Em parceria com a rede privada, foi lançado em 2011 a campanha "Saúde Não Tem 
Preço" com a distribuição de 12 (doze) medicamentos para o tratamento de hipertensão e diabetes de forma totalmente gratuita e em 2012 foram incorporados mais 7 (sete) para 0 tratamento de asma nessa mesma campanha custeados pelo MS.

Nota-se que não houve debate com a sociedade e nem com o Conselho Nacional de Saúde para tal supressão e isso põe em cheque direitos sociais adquiridos desde a Lei 8.142/90 que assegura a participação da sociedade. Ademais, tal supressão aponta para o retrocesso do Programa.

Ocorre que, o encerramento da "Rede Própria" pelo Governo Federal impacta o orçamento das famílias brasileiras, uma vez que, são expressivos os gastos com o uso contínuo de medicamentos de doenças crônicas ou medicamentos de alto custo. Portanto, há ainda que se ressaltar que os custos adicionais decorrentes destas medidas que eliminaram a farmácia popular Rede Própria sacrificam ainda mais os orçamentos domésticos da população economicamente mais pobre.

Conclui-se que os dados analisados apontam para a necessidade de fortalecer o debate acerca de políticas sociais voltadas ao programa que, estrategicamente, garante grandes avanços na inclusão do acesso aos usuários do SUS. Dessa forma, o PFPB, representa uma política pública de saúde importante para facilitar esse acesso.

\section{Referências}

1. Dallari SG. A Construção do Direito à Saúde no Brasil. Revista de Direito Sanitário, 2009, 9(3):9-34.

2. Brasil. Lei n. 8.080, de 19 de setembro de 1990. Dispõe sobre as condições para a promoção e recuperação da saúde, a organização e o funcionamento dos serviços correspondentes e dá outras providências. Disponível em:

http://www.planalto.gov.br/ccivil 03/leis/L8080.htm Acesso em 2.9.2017.

3. Brasil. Lei n. 8.142, de 28 de dezembro de 1990. Dispõe sobre a participação da comunidade na gestão do Sistema Único de Saúde (SUS) e sobre as transferências de recursos financeiros na área da saúde e dá outras providências. Disponível em: http://www.planalto.gov.br/ccivil 03/leis/L8142.htm Acesso em 2.9. 2017.

4. Brasil. Decreto n. 7508, de 28 de junho de 2011. Regulamenta a Lei no 8.080 , de 19 de setembro de 1990, para dispor sobre a organização do Sistema Único de Saúde- SUS, o planejamento da saúde, a assistência à saúde e a articulação interfederativa, e dá outras 
providencias. Disponível em: http://www.planalto.gov.br/ccivil 03/ ato20112014/2011/decreto/d7508.htm Acesso em 8.2.2018

5. Negri B. A Política de Saúde no Brasil nos anos 90: Avanços e Limites. Ministério da Saúde. Série B. Textos Básicos de Saúde. 2002. Disponível em: http://bvsms.saude.gov.br/bvs/publicacoes/a politica de saude.pdf Acesso em 1‥9. 2017.

6. Lobato LVC. Giovanella L. Políticas e Sistemas de Saúde no Brasil. Revista e ampliada. Rio de Janeiro: Editora Fiocruz/CEBES, 2014.

7. Fleury S, Ouverney AM. Política de Saúde: uma política social. Políticas e sistemas de saúde no Brasil. Revista e ampliada: Editora Fiocruz, 2014.

8. Pompeu GVM, Pimenta CAA. O princípio da Vedação do retrocesso social diante da crise econômica do século XXI. Direito e Desenvolvimento, João Pessoa, 2016, 6(12):216237.

9. Cunha JRA. Avanços e retrocessos do direito à saúde no Brasil: uma análise crítica. Rio de Janeiro, 2016.

10. Taveira CO, Marcal TB. Proibição do retrocesso social e orçamento: em busca de uma relação harmônica. RDA - Revista de Direito Administrativo, Rio de Janeiro, 2103, 264:161-186.

11- Braz KV. A aplicabilidade do Princípio do Retrocesso Social como meio de garantia constitucional ao direito à saúde. Cad. Ibero-Amer. Dir. Sanit., Brasília, 2016, 5(1): 78-101.

12. Lima GR, Cunha JRA. Análise do Projeto de Lei do Senado (PLS) № 200, de 2015, em face do Princípio da Proibição do Retrocesso Social. Cad. Ibero-Amer. Dir. Sanit., Brasília, 2016, 5(4):76-95.

13. Cunha JRA. Avanços e retrocessos do direito à saúde no Brasil: uma esperança equilibrista. Programa de Pós-Graduação em Política Social, Universidade de Brasília, 2014. Disponível em: http://repositorio.unb.br/handle/10482/16525 Acesso em 27.8.2017.

14. Brasil. Decreto n. 5.090, de 20 de maio de 2004. Regulamenta a Lei no 10.858, de 13 de abril de 2004, e institui o programa "Farmácia Popular do Brasil", e dá outras providências. Disponível em:

http://www.planalto.gov.br/ccivil 03/ ato20042006/2004/decreto/d5090.htm Acesso em 9.9.2017.

15. Brasil. Lei 10.858, de 13 de abril de 2004. Autoriza a Fundação Oswaldo Cruz Fiocruz a disponibilizar medicamentos, mediante ressarcimento, e dá outras providências. Disponível em: http://www.planalto.gov.br/ccivil 03/ ato2004-2006/2004/lei//10.858.htm Acesso em 9.9.2017. 
16. Silva RM. Caetano, R. Programa "Farmácia Popular do Brasil": caracterização e evolução entre 2004-2012. Ciências \& Saúde Coletiva, 2015, 20(10):2956. Disponível em: http://www.scielo.br/pdf/csc/v20n10/1413-8123-csc-20-10-2943.pdf Acesso em 9.9.2017.

17. Brasil. Portaria no 491/06, de 09 de março de 2006. Dispõe sobre a expansão do Programa "Farmácia Popular do Brasil". Disponível em:

http://portalarquivos2.saude.gov.br/images/pdf/2014/fevereiro/26/portaria-491.pdf Acesso em 8.2.2018.

18. Brasil. Portaria no 184/11, de 3 de fevereiro de 2011. Dispõe sobre o Programa "Farmácia Popular do Brasil". Disponível em:

http://bvsms.saude.gov.br/bvs/saudelegis/gm/2011/prt0184 0302 2011.html Acesso em 8.2.2018

19- Brasil. Portaria no 111, de 28 de janeiro de 2016. Dispõe sobre o Programa Farmácia Popular do Brasil (PFPB). Disponível em:

http://bvsms.saude.gov.br/bvs/saudelegis/gm/2016/prt0111 2801 2016.html Acesso em 24.9.2017.

20. Bardin L. Análise de conteúdo. Lisboa: Editora 70, 2011.

Recebido em: 23.3.2018

Aprovado em: 29.5.2018

\section{Como citar este artigo:}

Trindade JS. O fim da Rede Própria do Programa Farmácia Popular do Brasil e o Princípio da Proibição do Retrocesso Social. Revista Cadernos Ibero-Americanos de Direito Sanitário. 2018 abr./jun, 7(2):61-81. 